\title{
Interhemispheric observations of nightside ionospheric electric fields in response to IMF $B_{z}$ and $B_{y}$ changes and substorm pseudobreakup
}

\author{
T. K. Yeoman ${ }^{1}$, R. V. Lewis ${ }^{2}$, H. Khan ${ }^{1}$, S. W. H. Cowley ${ }^{1}$, J. M. Ruohoniemi ${ }^{3}$ \\ ${ }^{1}$ Department of Physics and Astronomy, University of Leicester, University Road, Leicester, LE1 7RH, UK \\ ${ }^{2}$ Ipswich School, Henley Road, Ipswich, Suffolk, IP1 3SG, UK \\ ${ }^{3}$ Johns Hopkins University, Applied Physics Laboratory, Laurel, MD 20707, USA
}

Received: 31 January 2000 / Revised: 31 March 2000 / Accepted: 14 April 2000

\begin{abstract}
HF radar data during equinoctial, small IMF $B_{y}$ conditions have enabled the ionospheric convection during the substorm growth phase and substorm pseudobreakup to be studied in both hemispheres. This has revealed both conjugate and non-conjugate convection behaviour during the substorm growth phase before and after the pseudobreakup onset. The nightside convection pattern is found to respond promptly to the southward turning of the interplanetary magnetic field (IMF) which impacts on the dusk flank of the magnetosphere due to an inclined phase front in the IMF in the case study presented. The subsequent interhemispheric observations of nightside convection are controlled by the IMF $B_{y}$ polarity. The time scale for the response to changes in the IMF $B_{y}$ component is found to be a little longer than for $B_{z}$, and the full impact of the IMF $B_{y}$ is not apparent in the nightside convection until after substorm pseudobreakup has occurred. The pseudobreakup itself is found to result in a transitory suppression in the ionospheric electric field in both hemispheres. This flow suppression is very similar to that observed in HF radar observations of full substorm onset, with the exception of a lack of subsequent poleward expansion.
\end{abstract}

Key words: Ionosphere (auroral ionosphere) Magnetospheric physics (magnetosphere-ionosphere interactions; storms and substorms)

\section{Introduction}

The extensive fields-of-view of high frequency (HF) ionospheric radars make them excellent instruments for the investigation of the spatial and temporal develop-

Correspondence to: T. K. Yeoman

e-mail: yxo@ion.le.ac.uk ment of the ionospheric electric fields during the three phases of the magnetospheric substorm (e.g. Morelli et al., 1995; Shand et al., 1998; Lewis et al., 1998). This is especially true for the SuperDARN network, which offers an extensive array of such radars in the Northern and Southern Hemispheres. The substorm electrojets are known to be highly time-dependent, and the ionospheric electric fields and conductivities combine to produce characteristic ground magnetic perturbations during the substorm expansion phase. During the substorm growth phase Lewis et al. (1997) demonstrated that the location of the HF radar backscatter was characterised by a systematic equatorward motion, thought to correspond to an equatorward motion of the structured precipitation of the expanding auroral oval. This pattern of expansion was only disturbed at expansion phase onset. During the substorm expansion phase dynamic convection features are observed, which correspond to azimuthally propagating field aligned current systems, which may be related to reconnection and bursty bulk flows in the magnetotail (Yeoman and Lühr, 1997; Yeoman et al., 1998). During the recovery phase HF radars can also provide valuable information on the morphology of auroral structures such as omega bands (Wild et al., 1999). The equatorward motion of the radar backscatter during the substorm growth phase first noted by Lewis et al. (1997) was demonstrated by Yeoman et al. (1999) (hereafter referred to as Paper 1) to be a highly conjugate feature. We examine the twodimensional ionospheric flow patterns from the interval presented in Paper 1, in both the Northern and Southern Hemispheres, in order to explore the response of the nightside ionospheric electric field to changes in the interplanetary magnetic field (IMF) $B_{z}$ and $B_{y}$ components and to substorm pseudobreakup.

The response of magnetospheric and ionospheric convection to changes in the upstream solar wind and IMF has generally been considered to start at the dayside, and subsequently expand towards the nightside (e.g. Etemadi et al., 1988; Todd et al., 1988). Recently, however, a case study by Ruohoniemi and Greenwald 
(1998) suggested an ionospheric response to a southward turning of the IMF within 2 min on the dayside and nightside. Rapid, global convection changes have also been inferred on a statistical basis by Ridley et al. (1998), although this interpretation remains controversial (Lockwood and Cowley, 1999). Recently Khan and Cowley (1999) presented a statistical study of ionospheric electric fields measured by the EISCAT radar, in which the ionospheric response expands from the dayside to the nightside over a time scale of $\sim 10 \mathrm{~min}$.

A mass of experimental evidence has confirmed that the IMF $B_{y}$ component influences the high-latitude ionospheric convection pattern (see e.g. Cowley, 1982 and references therein). The IMF $B_{y}$ component imposes a strong skewing force on the dayside high-latitude ionosphere (e.g. Cowley, 1981) which results, within the Northern Hemisphere, in anti-sunward flow being dragged towards the morning sector for IMF $B_{y}$ positive and towards the evening sector for $B_{y}$ negative (e.g. Reiff and Burch, 1985), with an opposite variation produced within the Southern Hemisphere. This $B_{y}$ effect is known to extend into the nightside (Rodger et al., 1984; Dudeney et al., 1991; Ruohoniemi and Greenwald, 1995). Rodger et al. (1984) described the asymmetric location in magnetic local time (MLT) of the Harang discontinuity as a function of IMF $B_{y}$, with its location within the Northern Hemisphere skewed $\sim 2$ hours westwards and the Southern Hemisphere $\sim 2$ hours eastwards, for a IMF $B_{y}$-component of $\sim 8 \mathrm{nT}$. Shand et al. (1998) demonstrated that when the ratio of IMF $B_{y}$ to $B_{z}$ was large $\left(B_{y} / B_{z}=2-4\right)$ then sufficient asymmetries were generated between the Northern and Southern Hemisphere ionospheric convection patterns to result in large-scale non-conjugacy even in flows driven by nightside processes.

Pseudobreakup is a term originally coined by Akasofu (1964) for an auroral brightening without a major expansion. Pseudobreakups have since then received relatively little study, but their differences and similarities with full-blown substorm onset has the potential to teach us about the fundamental physics of these processes, and about substorm triggering mechanisms and thresholds. Koskinen et al. (1993), Nakamura et al. (1994) and Aikio et al. (1999) provided multi-instrument observations of pseudobreakup which revealed similar signatures to full substorm onset but over a confined region. Pulkkinen et al. (1998) suggested that during pseudobreakup there is reconnection of open flux, based on data from Geotail and magnetohydrodynamic (MHD) simulations, just as in full substorm onset, but that this activity does not lead to Earthward flows. However, Nagai et al. (1998) presented observations of a flow burst due to tail reconnection during a pseudobreakup seen at $15 R_{E}$ by Geotail. The flow burst was short-lived and confined to near the neutral sheet, thus appearing to involve tail reconnection only of closed magnetic flux, and not the open tail lobe fields. Here we study the ionospheric electric field response to substorm onset directly with HF radars, examining a pseudobreakup response in both the Northern and Southern Hemisphere for the first time. Such an investigation of the high-latitude convection pattern, observed simultaneously in both hemispheres, can provide the opportunity to examine the time dependent nature of the coupling between the solar wind, magnetosphere and ionosphere during the substorm cycle.

In the present study an analysis of $\mathrm{HF}$ radar measurements of ionospheric convection during the growth and expansion phases is possible simultaneously in both the Northern and Southern Hemispheres. For this interval the Halley radar was centred on a frequency of $12.5 \mathrm{MHz}$, Goose Bay on $10.5 \mathrm{MHz}$, with similar backscatter coverage observed in both hemispheres (a $\sim 1^{\circ}$ latitude wider band of backscatter is observed in the Northern Hemisphere). Under small IMF $B_{y}$, equinoctial conditions, reasonably conjugate behaviour is observed. This is consistent with the observations reported by Shand et al. (1998). A detailed investigation of the flow patterns observed in both hemispheres, however, reveals non-conjugacies which may be attributed to IMF $B_{y}$, and allows an investigation of the time scale on which the magnetosphere responds to such changes.

\section{Instrumentation}

The ionospheric convection velocities in this study are provided by two poleward pointing HF backscatter radars, one located at Halley, Antarctica $\left(76^{\circ} \mathrm{S}, 27^{\circ} \mathrm{W}\right)$ and the other at Goose Bay, Labrador $\left(53^{\circ} \mathrm{N}, 60^{\circ} \mathrm{W}\right)$ from the international SuperDARN chain of HF radars (Greenwald et al., 1995). Figure 1 illustrates the fields of view (f-o-v) of the two radars, with the Northern Hemisphere radar (i.e. Goose Bay) mapped into the Southern Hemisphere, using the AACGM co-ordinate system (based on Baker and Wing, 1989). Each radar is frequency agile within the range $8-20 \mathrm{MHz}$ and is therefore sensitive to ionospheric plasma irregularities with wavelengths between $10 \mathrm{~m}$ and $30 \mathrm{~m}$. During standard operations the dwell time for each beam is $7 \mathrm{~s}$, giving a full 16 beam scan, covering $52^{\circ}$ in azimuth and over $3000 \mathrm{~km}$ in range (an area of over $4 \times 10^{6} \mathrm{~km}^{2}$ ), every $2 \mathrm{~min}$. Each of the range cells is $45 \mathrm{~km}$ along the line-of-sight (1-o-s) of the radar, and for each of the beams and ranges an 18 lag complex autocorrelation function is determined, from which the radial Doppler velocity can be deduced, along with backscatter power and spectral width. The f-o-vs of the two radars have been arranged to provide a sizeable conjugate overlap following inversion employing the AACGM geomagnetic co-ordinate system. A more complete description of the radar systems is given by Greenwald et al. (1985). The radar data are supplemented by ground magnetometer data from the Northern and Southern Hemispheres. In Antarctica, data from the British Antarctic Survey stations at Halley, and the Automatic Geophysical Observatory (AGO, Dudeney et al., 1998) stations A80 and A81 are presented. These instruments are fluxgate magnetometers with a time resolution of $1 \mathrm{~s}$ for the data presented here. In the Northern Hemisphere data from the Greenland magne- 


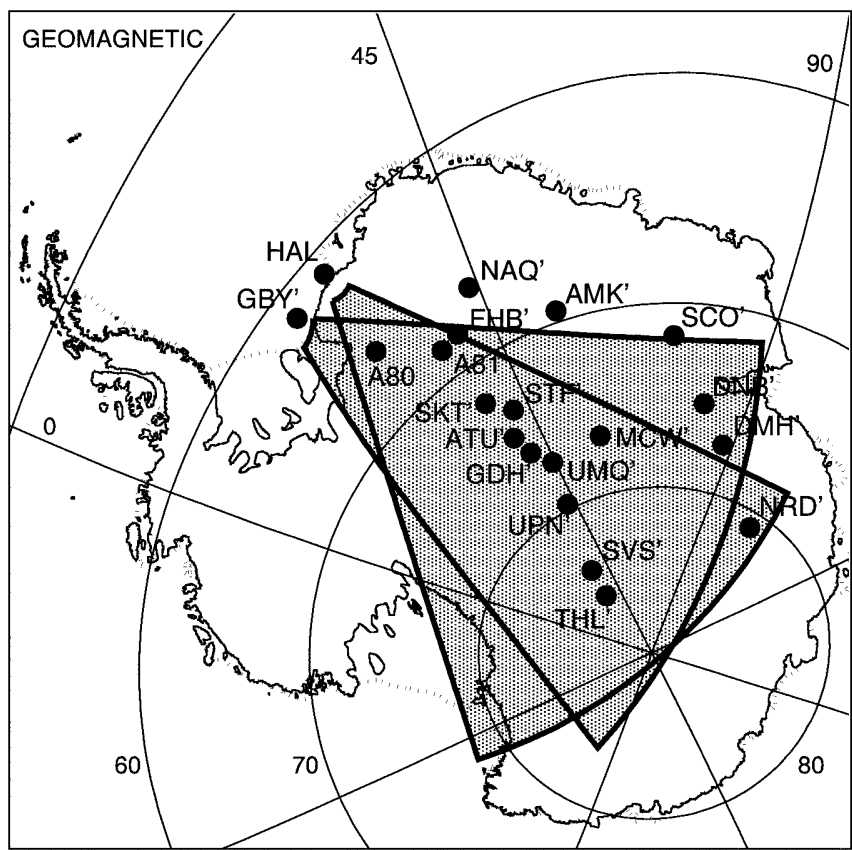

Fig. 1. Schematic of the PACE overlapping fields of view, comprising the Antarctic radar at Halley $(H A L)$ and the Northern Hemisphere radar at Goose Bay $(G B Y)$, and magnetometer stations from Greenland and Antarctica. The Northern Hemisphere instruments have been mapped into the Southern Hemisphere using the Altitude Adjusted Corrected Geomagnetic (AACGM) co-ordinate system, and are indicated by station names with primes

tometer array (Friis-Christensen et al., 1988) are presented. These instruments are also fluxgate magnetometers, in this case with $20 \mathrm{~s}$ time resolution. The deployment of the new AGOs provides a new magnetometer array for conjugate studies with the more extensive Greenland array. The locations of the Antarctic stations are indicated on Fig. 1, along with conjugate mappings (using the AACGM field model) of the locations of the Northern Hemisphere magnetometer stations.

\section{Observations}

\subsection{IMF data}

The interval of ground-based data under study, 0100 0400 UT on 17 March, 1996, may be set in context by the upstream conditions in the solar wind. The top three panels of Fig. 2 present $X, Y$ and $Z$ (GSM) components of the WIND magnetic field data (Lepping et al., 1995) from 2300 UT on 16 March, 1996, to 0400 UT on 17 March, 1996, when the spacecraft was located at $(X=102, \quad Y=48, Z=0) R_{E}$ GSE. Prior to this interval the IMF $B_{z}$ component had been northward or close to zero for the preceding 10 hours. The WIND spacecraft detected a sustained southward turning of the IMF at 0024 UT. Here we refine the calculation of the IMF delay from the WIND spacecraft to the subsolar magnetopause provided in Paper 1. The IMF delay from WIND is calculated using the technique of Khan and

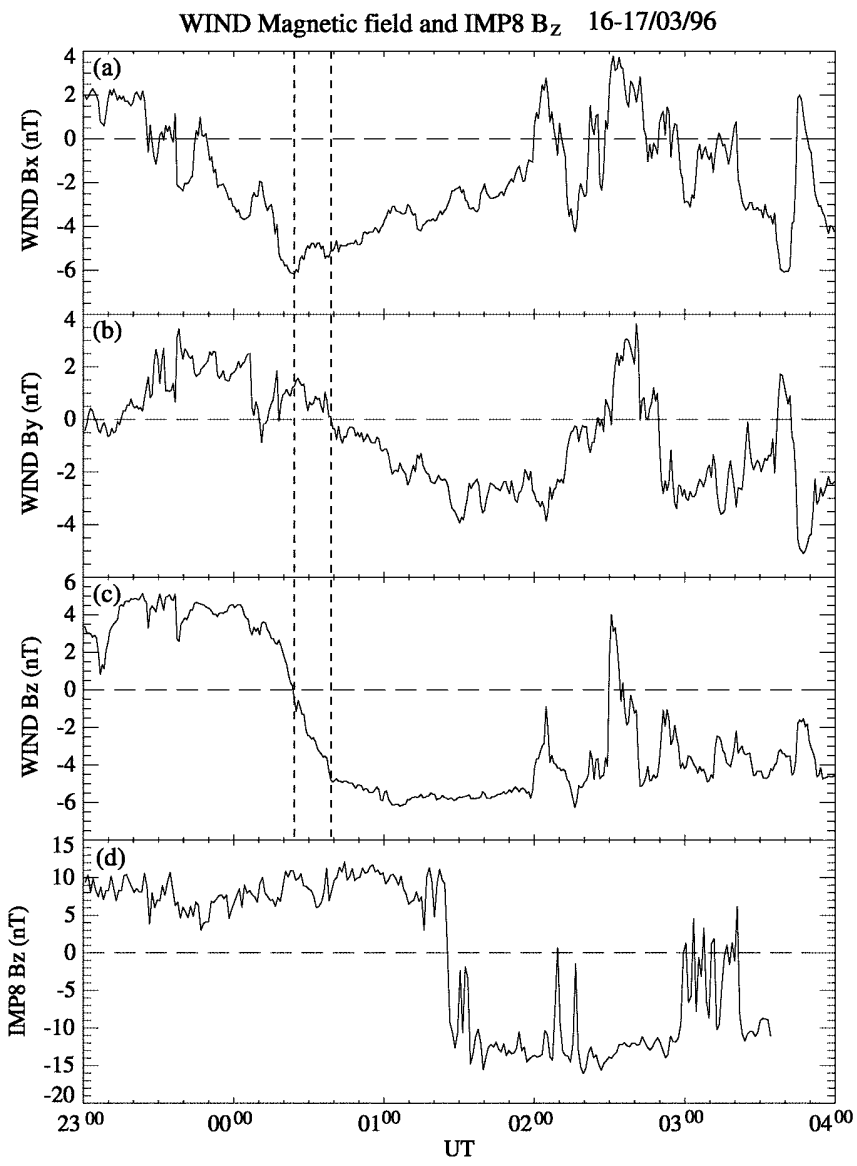

Fig. 2. a-c Upstream magnetic field data from the WIND spacecraft, between 2300 UT on 16 March, 1996 and 0400 UT on 17 March, 1996, presented in $X, Y, Z$ GSM co-ordinates. d Presents the GSM $Z$ component from the IMP-8 spacecraft. The vertical dashed lines indicate changes in polarity in the $B_{z}$ and $B_{y}$ components discussed in the text

Cowley (1999). This technique calculates the orientation of the "phase front" of the solar wind, assuming it is a tangential discontinuity, and includes a realistic estimate of the bowshock position, the fourfold deceleration of the solar wind on going across the bow shock, and subsequent further deceleration to an inflow speed of $20 \mathrm{~km} \mathrm{~s}^{-1}$ at the subsolar magnetopause. The delay deduced from this analysis is $67 \mathrm{~min}$, giving an onset time at the subsolar magnetopause of 01:31 UT \pm 10 $\min$, with the IMF phase front oriented at $160^{\circ}$ to the $X-Z$ plane. This analysis used data from an interval of $120 \mathrm{~min}$, centred on the southward turning. Calculations using a selection of various sub-intervals during this time suggests an error in the phase front orientation calculation of $\pm 8^{\circ}$. Supplementary data from the IMP-8 spacecraft (the $Z$ component of which is shown in Fig. 2d), lying at ( $X=-21, Y=24, Z=-8) R_{E}$ GSE in the magnetosheath, just outside the magnetospheric flank at an MLT of $\sim 2100$, shows the IMF southward turning at $0125 \mathrm{UT}$. Assuming the deceleration of the solar wind flow across the bowshock, but no further deceleration due to flow stagnation for the IMP-8 location near the magnetospheric flank, this data is 
consistent with the WIND data for an IMF phase front oriented at $\sim 135^{\circ} \pm 15^{\circ}$ to the $X-Z$ plane. These two phase front calculations are reasonably consistent considering that a planar phase front with a constant orientation as it moves between the WIND spacecraft and the bowshock must be assumed. Assuming a phase front which lies somewhere between these two estimates, we would conclude that the IMF discontinuity impacted on the bowshock at 1500-1800 MLT, and that the effect of the southward turning of the IMF was imposed on a broad region of the magnetopause at a time close to 0123 UT, reaching the nightside ionosphere at 0125 UT. This is some $5 \mathrm{~min}$ later than the delay calculated in Paper 1. Thus we can conclude that the flow response occurred near-simultaneously on the dayside and nightside ionosphere for this rather unusual IMF phase front orientation. Figure 2 demonstrates that the time sequence of the IMF at WIND (the nightside ionosphere) evolved from a $B_{z}$ north, $B_{y}=0$ configuration before 23:15 UT on 16 March (0016 UT on 17 March), to a $B_{z}$ north, $B_{y}$ positive configuration until 0024 UT (0125 UT) when $B_{z}$ south, $B_{y}$ positive conditions prevail apart from a brief interval near 0010 UT (0111 UT) when $B_{y}$ is near zero. This then evolves to $B_{z}$ south, $B_{y}$ negative conditions at 0039 UT (0140 UT). The polarity changes in the IMF $B_{z}$ and $B_{y}$ components measured at WIND at 0024 and 0039 UT respectively are indicated in Fig. 2 with vertical dashed lines.

\subsection{Magnetometer data}

Figure 3 presents $H$ and $Z$ component magnetometer data from both the Greenland and Antarctic arrays between 0100-0400 UT on 17 March, 1996. Clear substorm-associated bays in the $H$ component magnetic field, with associated $\mathrm{Pi} 2$ pulsations, can be seen at 0150 and 0230 UT. Another substorm breakup, not quite so clear in the Antarctic data, occurs at 0310 UT. Here we concentrate on the 0150 expansion phase onset, which is a small and localised event, with the $Z$ component magnetic field data clearly indicating that the centre of the substorm electrojet lies between the stations A80 and A81 (between latitudes of $66.3^{\circ}$ and $68.6^{\circ} \mathrm{S}$ AACGM). The event lasts for approximately $7 \mathrm{~min}$. The 0230 event, which is of significantly larger amplitude at the stations illustrated in Fig. 3, starts at the same latitude, subsequently moving poleward of station A81. In the Northern Hemisphere the 0150 event is again seen to be a small localised event centred between NAQ and FHB (between latitudes of $67.0^{\circ}$ and $68.7^{\circ} \mathrm{N}$ AACGM; note the very close conjugacy between A81 and FHB in Fig. 1). There is no evidence of any poleward expansion of the 0150 UT event in the Northern Hemisphere (insufficient magnetometer coverage exists to confirm this in the Southern Hemisphere), and it would thus be classified as a pseudobreakup. In the Northern Hemisphere data the 0230 event is again larger, and is centred (a) 17/03/96 X component

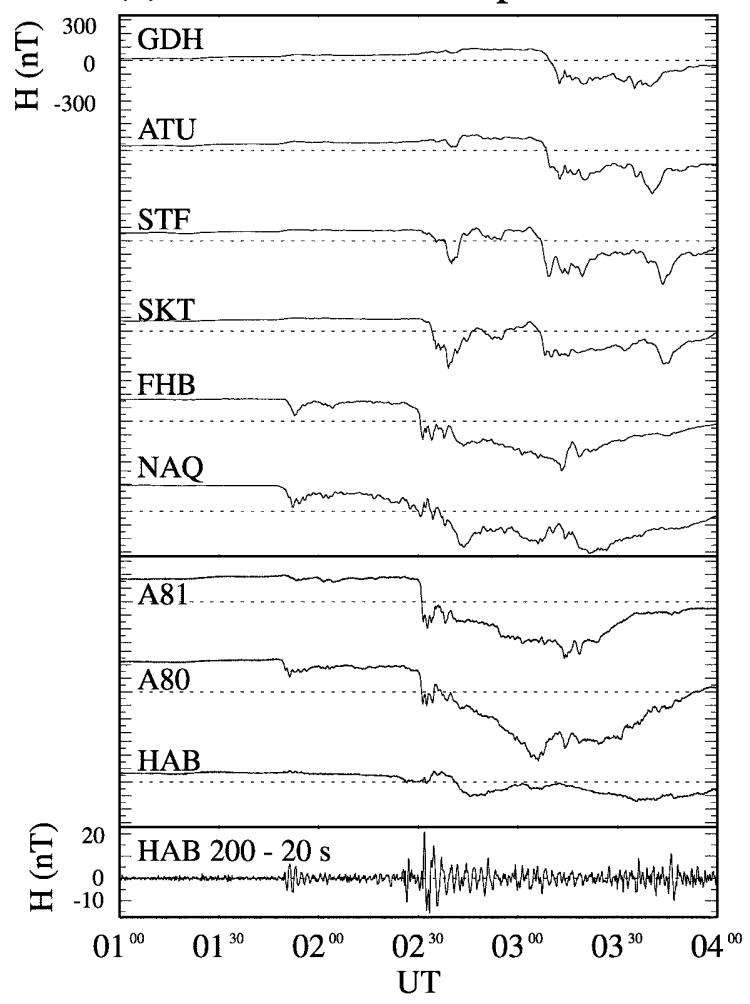

Fig. 3a, b. Greenland and Antarctic magnetograms for 0100 UT 0400 UT on 17 March 1996. a $H$ (positive horizontal geomagnetic north) and b $Z$ (positive vertically down, Greenland, and positive

\section{(b) Z component}

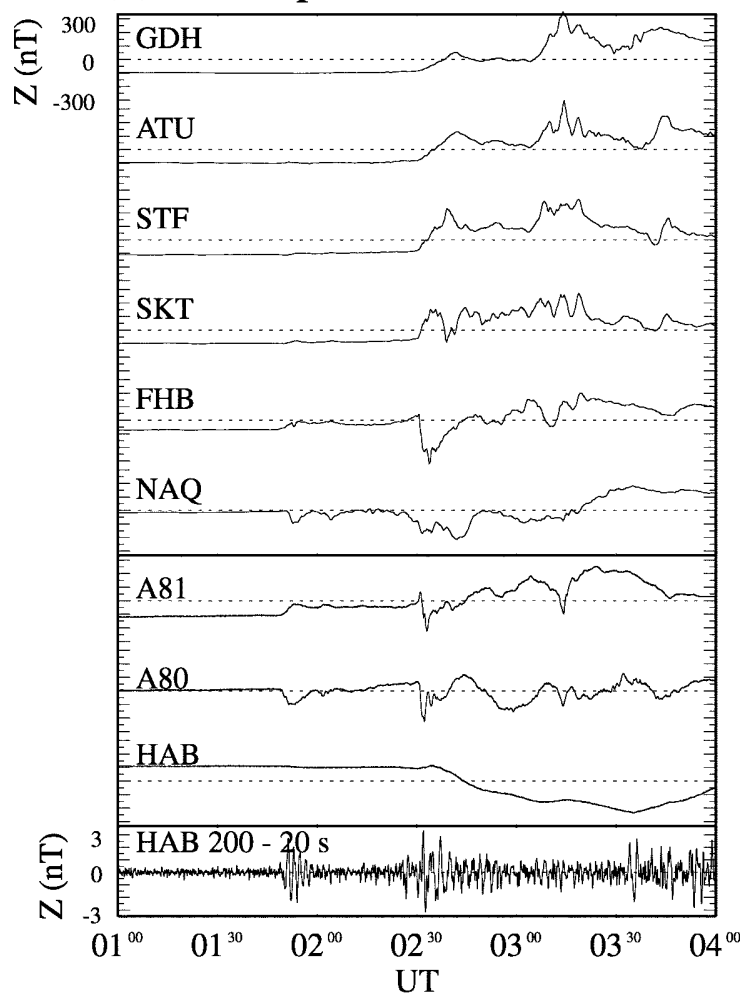

vertically up, Antarctica) components are displayed. Bandpass filtered traces from HAL reveal the presence of Pi2 pulsations, indicating substorm expansion phase onsets 
between FHB and SKT (between latitudes of $68.7^{\circ}$ and $72.7^{\circ} \mathrm{N}$ AACGM). This onset can clearly be seen to expand poleward as far as ATU.

\subsection{Radar data}

The equatorward motion of the radar backscatter measured at Halley and Goose Bay during this interval, and its relation to the expanding polar cap during the substorm growth phase has been discussed in Paper 1 . There, a sharp equatorward movement of HF radar backscatter was noted at around 0120 UT (such motion was only clearly observed after 0125 UT) and was accompanied by strong equatorward plasma flow. This equatorward expansion of backscatter was noted to occur conjugately in both hemispheres in response to a southward turning of the IMF, and was well described by a calculation based on the addition of open magnetic flux to the polar cap during the substorm growth phase.

Here we concentrate on the two-dimensional ionospheric convection patterns measured in both hemispheres by the SuperDARN radars, and the ionospheric flow dynamics in response to changes in the IMF $B_{y}$ component and to the substorm pseudobreakup. Figure 5 presents ionospheric flow data from six illustrative 2-min scans of the SuperDARN Goose Bay and Halley radar systems. Convection data for each scan is presented in a magnetic local time-magnetic latitude coordinate system in the Northern and Southern Hemispheres, with local midnight lying at the bottom of each panel. Line-of-sight (1-o-s) velocity is colour coded, with flow away from the radar shown in red and flow toward the radar shown in blue. Overlaid on the colour-coded 1-o-s velocities are a number of estimates of the horizontal flow vector, calculated using a beamswinging algorithm where the flow component parallel to the $L$-shell is assumed constant across the scan (Villain et al., 1987; Ruohoniemi et al., 1989). The selected scans are chosen to illustrate typical convection during the various upstream IMF regimes identified from Fig. 2 in Sect. 3.1.

Figure $4 \mathrm{a}$ presents Northern and Southern Hemisphere scans from 0102-0104 UT, corresponding to an interval when the nightside ionosphere was under the influence of $B_{z}$ north, $B_{y}$ positive conditions (see Sect. 3.1). At this time a non-conjugacy can be observed, with a band of strong poleward flow visible only in the Southern Hemisphere data. This non-conjugacy is likely to be due to interhemispheric differences in transpolar arc structure (Craven and Frank, 1991). Figure 4b presents Northern and Southern Hemisphere scans from 0114 0116 UT, corresponding to an interval when the nightside ionosphere was under the influence of $B_{z}$ north, $B_{y}=0$ conditions (see Sect. 3.1). The convection patterns from both hemispheres now reveal highly conjugate behaviour, with equatorward and westward flows observed, indicating that both radars are lying in the eastward electrojet, just west of the nightside convection reversal region. Figure $4 \mathrm{c}$ illustrates the flows some time later, at 0136-0138 UT, when IMF conditions have shifted to $B_{z}$ south, $B_{y}$ positive conditions, early in the growth phase of the substorm. A clear evolution of the flow has taken place, with the Southern Hemisphere radar observing the nightside convection reversal and a little of the westward electrojet, whereas the Northern Hemisphere radar observes only westward electrojet flows, even though the region from which data is recorded lies to the west of the Southern Hemisphere backscatter. Thus a clear non-conjugacy has been introduced into the data following the IMF $B_{z}$ southward turning as the strength of the $B_{y}$ component has increased.

By 0144 UT (Fig. 4d), the IMF conditions have evolved, with a strengthening southward component, and with $B_{y}$ having turned negative. However, the ionospheric flows measured in the conjugate radar fields of view show very little evolution between Fig. 4c, d, the change in IMF $B_{y}$ having yet to impact on the nightside ionosphere. The convection patterns in both hemispheres remain steady in this configuration until 0152 UT. Figure 4e presents the ionospheric flow patterns from the two radars at 0152-0154 UT. This is the time of the pseudobreakup onset. The radar backscatter coverage in both hemispheres is reduced, and a clear suppression of ionospheric flow is seen in both hemispheres. Finally Fig. 4f presents the ionospheric convection after the pseudobreakup, when the flow has recovered to magnitudes similar to the pre-breakup values. At this time the flow has clearly undergone a reorientation, with the Northern Hemisphere radar measuring predominantly westward flow. In the Southern Hemisphere equatorward and eastward flow is observed. Thus an opposite non-conjugacy to that observed earlier in Fig. 4c, d has been introduced between the Northern and Southern Hemispheres. Figure $4 \mathrm{~d}-\mathrm{f}$ thus suggests that the time required for the development of a convection pattern expected for negative $B_{y}$ conditions in the nightside ionosphere is some 6-12 min longer than that required to respond to the effects of IMF $B_{z}$ negative.

An alternative technique for the visualisation of the ionospheric convection patterns during the interval is presented in Fig. 5. Here the spherical harmonic potential fitting or "potential map" technique (Ruohoniemi and Baker, 1998) has been applied to calculate the potential pattern which is most consistent with the lineof-sight velocities determined by the full array of Northern Hemisphere SuperDARN radars (insufficient radar coverage existed in the Southern Hemisphere to provide a meaningful map). In Fig. 5 three 2 min intervals are presented in MLT-geomagnetic latitude coordinates for latitudes ranging from $60^{\circ}$ to $80^{\circ}$ and local times from 21 to 03 MLT. The ionospheric flow vectors deduced by combining the measured line-ofsight velocities with the transverse velocity components implied by the fitted potential pattern are displayed as arrows and are colour-coded according to flow magnitude. Contours of electric equipotentials are also displayed, with solid (dashed) lines indicating negative (positive) potentials. In these maps the electric potential is expanded to order 8, with the lower latitude limit of the convection pattern fixed to $60^{\circ}$. No temporal median filtering has been applied. The 
SUPERDARN PARAMETER PLOT Goose Bay and Halley: velocity

(a)

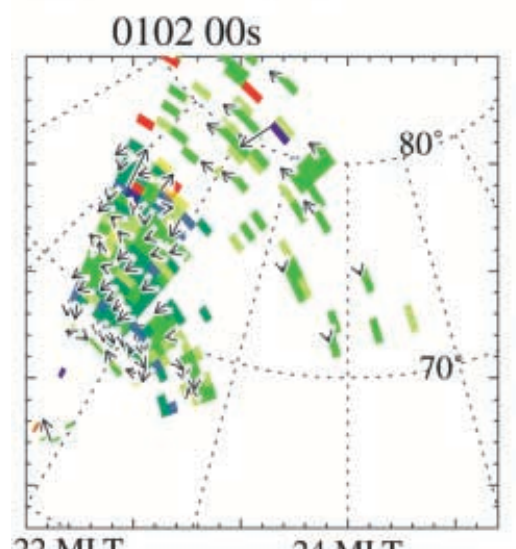

24 MLT

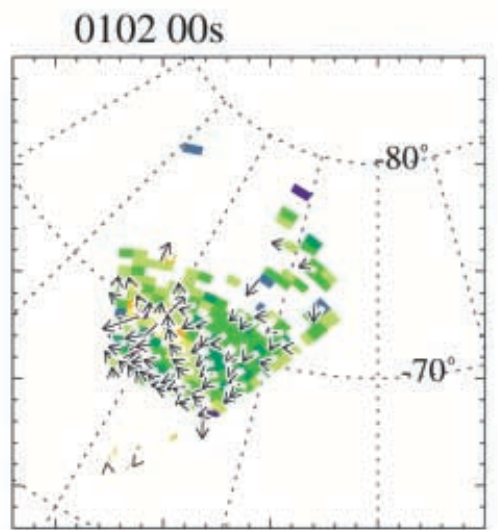

22 MLT

24 MLT

Fig. 4a-f. A sequence of convection maps for 2-min scans of the Goose Bay (top row) and Halley (bottom row) radars. Colour-coded line-of-sight velocity and flow vectors estimated using a beamswinging

$011359 \mathrm{~s}$
17 Mar 1996

(c) $B z-\mathrm{ve}, B y+\mathrm{ve}$
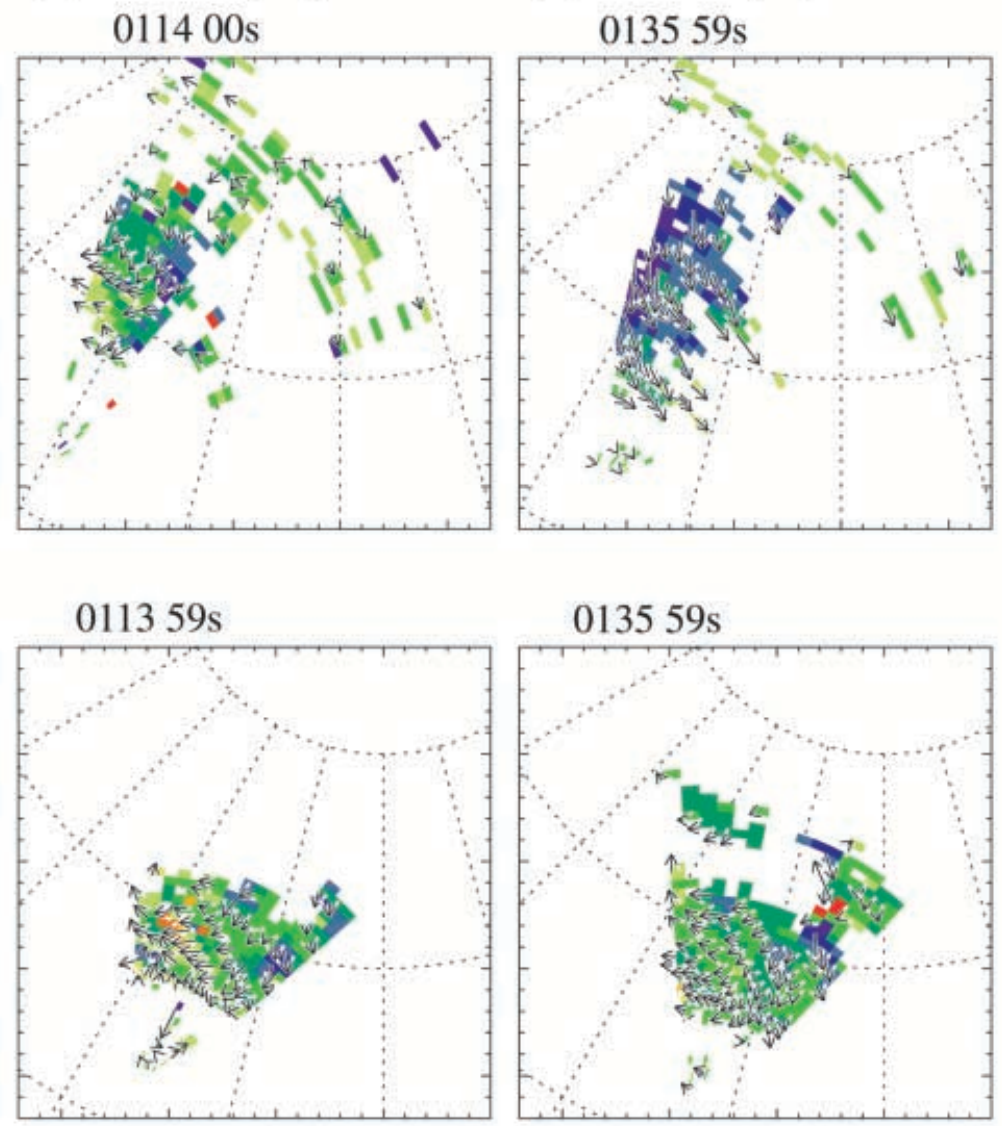

Beamswung vectors

$\uparrow$

$1000 \mathrm{~m} \mathrm{~s}^{-1}$

Ionospheric scatter only algorithm are presented in magnetic local time-magnetic latitude coordinates. The scan start time and the prevailing IMF/geomagnetic conditions are indicated at the top of each column potential pattern calculation is stabilised by the statistical model of Ruohoniemi and Greenwald (1996) for IMF magnitude $0<B_{t o t}<4 \mathrm{nT}, B_{z}$ negative conditions. A fixed model rather than an IMF-driven model is chosen in order to ensure that the calculated pattern is not directly influenced by any variations in the IMFdriven statistical model. In fact the calculated equipotential pattern is insensitive to the exact upstream conditions assumed. Figure 5a presents the convection pattern from 0144 to 0146 UT. The duskward shift of the nightside convection reversal region noted in the Northern Hemisphere in Fig. 4 is clearly visible. In Fig. 5b, showing data from 0152-0154 UT, during the pseudobreakup event, the suppression of ionospheric electric field, and hence flow, is clearly illustrated by a "pushing apart" of the equipotential contours. This feature is visible in the potential maps for 4-6 min, and is observed at the latitude of, and poleward of, the centre of the electrojet $\left(\sim 68^{\circ}\right.$, as identified in the magnetograms of Fig. 3). The convection reversal region (most easily identified by the first negative and positive potential contours, which are marked in bold in Fig. 5 for clarity) moves eastward at the onset of the pseudobreakup. In the bottom panel of Fig. 5 the ionospheric electric field has recovered to its pre-onset levels, and the flow in the Northern Hemisphere has returned to a more symmetrical configuration. The convection reversal region in Fig. 5c is eastward of that in Fig. 5a, but westward of that observed during the pseudobreakup itself.

\section{Discussion}

An interval of data has been presented detailing the evolution of the nightside ionospheric convection pattern measured simultaneously in two large, magnetically conjugate fields-of-view in the Northern and Southern Hemisphere. The observed ionospheric convection responds to an evolving upstream IMF configuration and 


\section{SUPERDARN PARAMETER PLOT Goose Bay and Halley: velocity

(d) $B z$-ve, $B y$-ve

$014359 \mathrm{~s}$

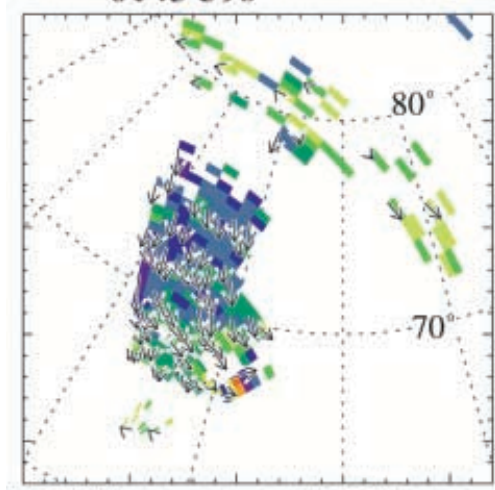

22 MLT

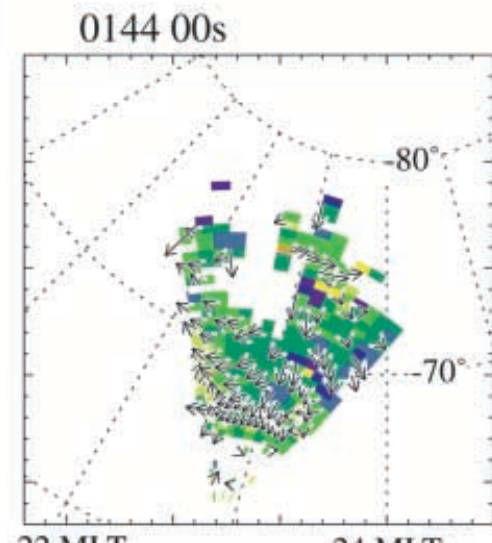

22 MLT (e) Pseudobreakup $015159 \mathrm{~s}$

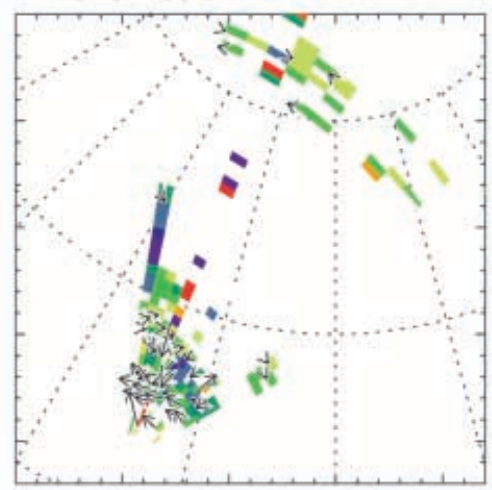

$015200 \mathrm{~s}$

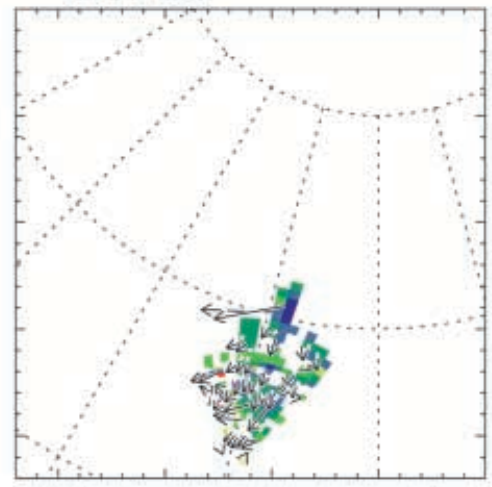

(f) Flow recovery

$020400 \mathrm{~s}$

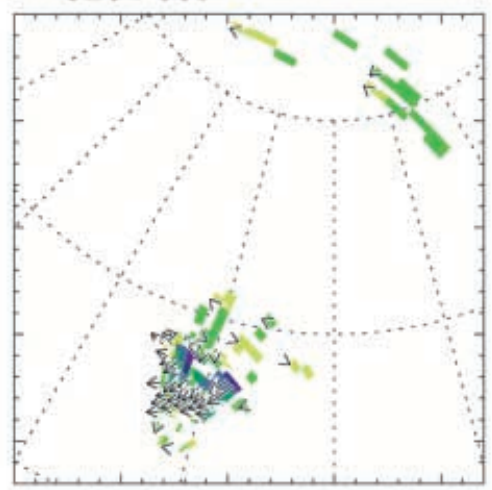

Beamswung vectors

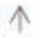

$1000 \mathrm{~m} \mathrm{~s}^{-1}$ Ionospheric
scatter only

Fig. 4a-f. (contd.)

to a pseudobreakup observed in the nightside magnetosphere. The data are now discussed with reference to three important issues in magnetospheric dynamics; namely the time scale over which the magnetosphere evolves in response to IMF changes at various magnetic local times, the nature of the magnetospheric and ionospheric response to changes in IMF $B_{z}$ and $B_{y}$ on the nightside, and the magnetospheric/ionospheric response to substorm pseudobreakup.

\subsection{Magnetospheric response time to changes in the IMF}

There is a considerable current controversy over the MLT evolution of the magnetospheric response to changes in the upstream solar wind and IMF conditions. In a recent paradigm, the response has been considered to be a steady evolution, starting near magnetic local noon, and propagating away from this location (Etemadi et al., 1988; Todd et al., 1988; Khan and Cowley, 1999). All three of these studies were consistent with a minimum delay between the upstream conditions and the magnetospheric response occurring close to 1400 MLT, the shift from local noon being ascribed to the spiral structure of the IMF. Theoretically this evolution of flow may be understood as follows: the initial flow results from the interaction between the dayside magnetopause and the IMF, with flow being driven by reconnection appending new open flux onto the dayside polar cap. Subsequently the flow region expands as the polar cap relaxes back to a new equilibrium (Cowley and Lockwood, 1992). However, more recent case studies (Ruohoniemi and Greenwald, 1998) and statistical studies (Ridley et al., 1998) have suggested a more global response may occur, on time scales of as little as $2 \mathrm{~min}$. The physical mechanism generally proposed for this rapid response is a fast mode $\mathrm{MHD}$ wave, although the draping of the IMF around the magnetopause may also play an important role (Shepherd et al., 1999). The case study presented here indicates how, at least for some orientations of the upstream IMF, these two pictures may be reconciled. The phase front of the IMF inferred from the WIND magnetic field data presented in Fig. 2 is 


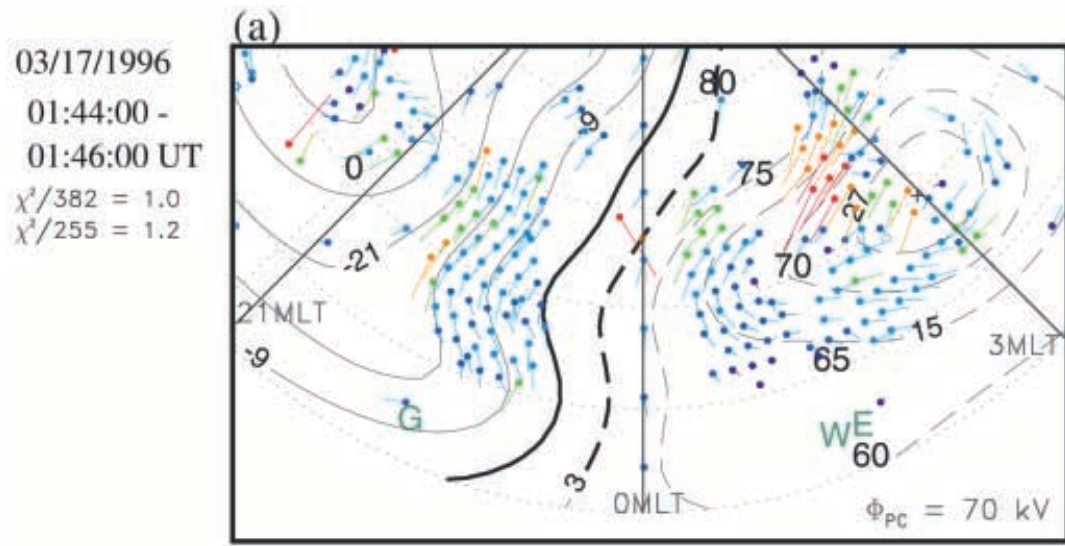

(b)

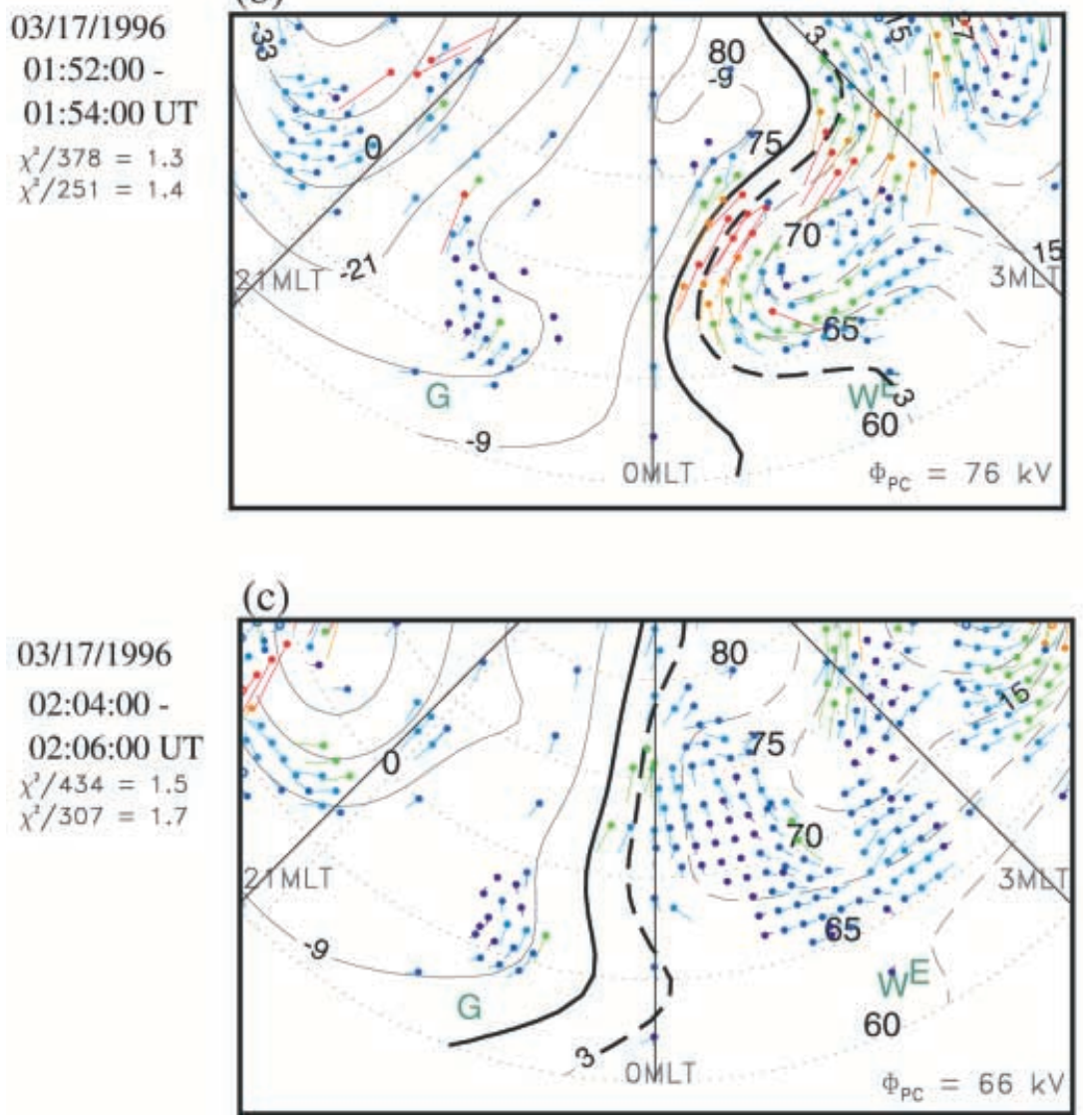

APL MODEL

$0<\mathrm{BT}<4$

Bz-
$2000 \mathrm{~m} / \mathrm{s}$

$\mathrm{m} / \mathrm{s}$

1000

800

600

400

200
Fig. 5a-c. Flow vectors and equipotential contours for the Northern Hemisphere data presented in Fig. 4d-f, in magnetic local time-magnetic latitude coordinates. These data are calculated using the potential map technique (see text for details). The first positive and negative potential contours are marked in bold to emphasise the location of the convection reversal region strongly skewed from the Parker spiral direction, leading to a point of first impact of the IMF on the dayside bow shock well away from local noon. This determination of the IMF phase front is consistent with magnetic field data from the IMP-8 spacecraft (Fig. 2d) within the Earth's magnetosheath. The deduced IMF phase front orientation could lead to a miscalculation of the travel time of the IMF southward conditions from WIND to the Earth. It also has a profound influence on the first contact position of the IMF and magnetopause. This phase front orientation would lead to very similar onset times for flow responses in the dayside and nightside sectors, whilst being fully consistent with the theoretical picture of Cowley and Lockwood (1992).
4.2 Ionospheric convection response to IMF $B_{z}$ and $B_{y}$

The response of the HF radar data (initially an equatorward motion of the radar backscatter location) to the southward turning of the IMF, as presented in Paper 1, is consistent with the IMF travel time calculation discussed. At times of small IMF $B_{y}$ a high degree of conjugacy has been demonstrated between the resulting ionospheric convection in the Southern and Northern Hemisphere radar data, as illustrated in Fig. 4b. Subsequent to this interval non-conjugacies are observed in the ionospheric convection patterns, with the nightside convection reversal moving duskward in the Northern Hemisphere under positive IMF $B_{y}$ 
conditions (Fig. 4c), then dawnward when $B_{y}$ turns negative (Fig. 4f). Opposite behaviour is observed in the Southern Hemisphere. This distortion of the twin cell convection pattern is observed close to local midnight, and is of a significant magnitude: an azimuthal motion of the convection reversal of $\sim 7^{\circ}$ per nT of the IMF $B_{y}$ component may be derived from Fig. 4. The observed skewing of the ionospheric convection pattern is in accord with the model put forward by Cowley (1981). In this model the interaction of the IMF $B_{y}$ component with the open magnetosphere not only imposes an azimuthal component into the ionospheric flow in the cusp region, but $B_{y}$ also directly enters the magnetotail. This leads to an asymmetric addition of magnetic flux into the magnetotail lobes and a twisting of the tail current sheet, which distorts the nightside ionospheric convection pattern and displaces the auroral oval (Cowley et al., 1991). The entry of $B_{y}$ into the magnetosphere has been demonstrated to have the largest effect near local midnight (Cowley and Hughes, 1983; Wing et al., 1995). This field distortion then leads to non-conjugacy, in the AACGM coordinate system, of regions of Northern and Southern Hemisphere ionosphere which are in fact magnetically connected. The azimuthal displacement of the nightside convection reversal presented here at latitudes of $70^{\circ}-80^{\circ}$ geomagnetic latitude are in the same sense as the displacement of the Harang discontinuity noted by Rodger et al. (1984) from magnetometer data. The size of the effect is larger, however, (Rodger et al. (1984) having noted a movement of some $2^{\circ}-3^{\circ} \mathrm{nT}^{-1}$ at magnetic latitudes close to $60^{\circ}$ ). The magnitude of the effect seems more consistent with the statistical study of Ruohoniemi and Greenwald (1995), who noted a $2.5 \mathrm{~h}$ MLT shift in the location of the nightside zonal convection reversal boundary between IMF $B_{y}$ positive and negative conditions.

The case study presented here has, in addition, provided an opportunity to determine the time scale over which the ionospheric convection responds to changes in the IMF $B_{y}$ component. Figure $4 \mathrm{~d}$ demonstrates that a convection pattern expected for positive $B_{y}$ conditions persists until at least $0146 \mathrm{UT}$, some $6 \mathrm{~min}$ after the anticipated arrival of the effects of IMF $B_{y}$ negative conditions at the nightside ionosphere. In fact a convection pattern expected for $B_{y}$ negative conditions is not observed clearly until after the substorm pseudobreakup at 0152 UT, thus a 6-12 min delay in the nightside ionospheric convection response to IMF $B_{y}$ with respect to the IMF $B_{z}$ response is suggested. Thus the ionospheric response to IMF $B_{y}$ changes on the nightside appears to be slower than for changes in IMF $B_{z}$. If the asymmetry in the nightside ionospheric convection is a consequence of the asymmetric magnetotail lobe field due to the penetration of the IMF $B_{y}$ into the magnetosphere, as suggested by Cowley (1981) and Cowley et al. (1991), then this might be expected. It seems reasonable that the imposition of an opposite skewing force as the polarity of IMF $B_{y}$ changes will have to reverse the pre-existing magnetotail asymmetry, and then impose an opposite asymmetry, and that this reorientation will occur over a longer time scale than the response to the IMF $B_{z}$ changes. Such an evolution of the magnetotail will be accomplished most directly on open magnetic field lines, and the fact that the full reorganisation of the ionospheric convection does not occur until after the substorm pseudobreakup may indicate that the effect is most easily accomplished after reconnection has occurred in the magnetotail. It is possible that the increased conductivity in both ionospheres due to the pseudobreakup may also play a role in producing the reorganisation of the convection.

\subsection{Ionospheric response to substorm pseudobreakup}

The substorm pseudobreakup observed at $0150 \mathrm{UT}$, lasting for $\sim 7 \mathrm{~min}$ in magnetic field data, results in a transitory reduction in the backscatter measured by both radars (Fig. 4d). This is accompanied by a shortlived suppression in the ionospheric electric field measured by the radars in both hemispheres (Figs. 4e, 5b), which lasts 4-6 min. The flow suppression occurs over the latitude where the magnetic signature of the substorm electrojet is centred, and extends a few degrees poleward of this location. This flow suppression is very similar to that observed in HF radar observations of full substorm onset (Morelli et al., 1995), with the exception of a lack of subsequent poleward expansion. The electric field suppression is thought to be a consequence of enhanced ionospheric conductivity resulting from energetic particle precipitation into the ionosphere. It occurs reasonably conjugately in both hemispheres, and appears to play a role in the reorganisation of the flow in response to the IMF $B_{y}$ change. The spatial and temporal extent of these interhemispheric observations of the ionospheric electric fields presented here, therefore, are in agreement with previous Northern Hemisphere observations (Koskinen et al., 1993; Nakamura et al., 1994; Aikio et al., 1999), occurring over at least $1 \mathrm{~h}$ of MLT and $5^{\circ}$ of geomagnetic latitude (these determinations being limited by the HF radar data coverage) with a duration of $\sim 6$ minutes. Koskinen et al. (1993) originally suggested that the ionospheric conductivity might determine whether or not a pseudobreakup or a full substorm onset occurred. A combination of a calculation of the equivalent currents from the A80 magnetometer and the electric field derived from the Halley radar, where radar data are available from the overlying range gate, suggests a height-integrated Hall conductivity of $\sim 20 \mathrm{~S}$ during both the pseudobreakup event and the later substorm. This is consistent with the suggestion of more recent work by Nakamura et al. (1994) and Aikio et al. (1999), that the ionospheric conductivity does not play such a direct role in determining the nature of the onset.

\section{Conclusions}

HF radar data during an equinoctial period, during which a prolonged interval of northward IMF gave way to a southward IMF with a small IMF $B_{y}$ component 
have enabled the ionospheric convection during the substorm growth phase and substorm pseudobreakup to be studied in both hemispheres. The nightside convection pattern is found to respond promptly to the southward turning of the IMF, once a detailed calculation of the transit time from WIND to the nightside ionosphere is performed. This reveals a highly inclined phase front in the IMF which impacts first on the dusk flank of the magnetosphere. When the IMF $B_{y}$ component is near zero, highly conjugate ionospheric convection patterns are observed. When the IMF $B_{y}$ component reaches magnitudes of $\sim 2 \mathrm{nT}$ the interhemispheric observations of nightside convection are controlled by the $B_{y}$ polarity. The time scale for the response to changes in the IMF $B_{y}$ component is found to be a little longer than for $B_{z}$, presumably as a consequence of the pre-existing asymmetry in the magnetotail configuration imposed by the preceding $B_{y}$ polarity (Cowley, 1981). The full impact of IMF $B_{y}$ is not apparent in the nightside convection until after substorm pseudobreakup has occurred. The pseudobreakup itself is found to result in a conjugate, transitory suppression in the ionospheric electric field in both hemispheres, lasting $\sim 6 \mathrm{~min}$ and with a scale size of at least $500 \mathrm{~km}$ in latitude and longitude. This flow suppression is very similar to that observed in HF radar observations of full substorm onset (Morelli et al., 1985), with the exception of a lack of subsequent poleward expansion. The ionospheric Hall conductivity appears similar in both pseudobreakup and full substorm onset events, and thus does not appear to control the type of onset observed.

Acknowledgements. We are grateful to Ron Lepping and Keith Ogilvie, principal investigators on the WIND spacecraft MFI and SWE instruments respectively. The Halley radar is funded jointly by the UK Natural Environment Research Council and the US National Science Foundation, Department of Polar Programs, under grant DPP-8602975. Operation of the Goose Bay radar is supported by NSF Grant ATM-9502993 to the Johns Hopkins University Applied Physics Laboratory. HK was supported by a University of Leicester postgraduate studentship during this work.

Topical Editor G. Chanteur thanks C. Senior and another referee for their help in evaluating this paper.

\section{References}

Aikio, A. T., V. A. Sergeev, M. A. Shukhtina, L. I. Vagina, V. Angelopoulos, and G. D. Reeves, Characteristics of pseudobreakups and substorms observed in the ionosphere, at the geosynchronous orbit, and in the midtail, J. Geophys. Res., 104, 12,263, 1999.

Akasofu, S.-I., The development of the auroral substorm, Planet. Space Sci., 12, 273, 1964.

Baker, K. B., and S. Wing, A new magnetic coordinate system for conjugate studies at high latitudes, J. Geophys. Res., 94, 9139, 1989.

Cowley, S. W. H., Magnetospheric asymmetries associated with the Y-component of the IMF, Planet. Space Sci, 29, 79, 1981.

Cowley, S. W. H., The cause of convection in the Earth's magnetosphere: a review of developments during the IMS, $J$. Geophys. Res., 20, 531, 1982.
Cowley, S. W. H., and W. J. Hughes, Observation of an IMF sector effect in the Y magnetic field component at geostationary orbit, Planet. Space Sci., 31, 73, 1983.

Cowley, S. W. H., and M. Lockwood, Excitation and decay of solar wind-driven flows in the magnetosphere-ionosphere system, Ann. Geophysicae, 10, 103, 1992.

Cowley, S. W. H., J. P. Morelli, and M. Lockwood, Dependence of convective flows and particle precipitation in the high latitude dayside ionosphere on the $\mathrm{X}$ and $\mathrm{Y}$ components of the interplanetary field, J. Geophys. Res., 96, 5557, 1991.

Craven, J. D., and L. A. Frank, Diagnosis of auroral dynamics using global auroral imaging with emphasis on large-scale evolutions, Auroral physics, Eds. C.-I. Meng, M. J. Rycroft, and L. A. Frank, CUP, 1991.

Dudeney, J. R., R. I. Kressman, and A. S. Rodger, Automated observatories for geospace research in polar regions, Antarct Sci, 10, 192, 1998.

Dudeney, J. R., A. S. Rodger, M. Pinnock, J. M. Ruohoniemi, K. B. Baker, and R. A. Greenwald, Studies of conjugate plasma convection in the vicinity of the Harang Discontinuity, J. Atmos. Terr. Phys., 53, 249-263, 1991.

Etemadi, A., S. W. H. Cowley, M. Lockwood, B. J. I. Bromage, D. M. Willis, and H. Lühr, The dependence of high latitude dayside ionospheric flows on the north-south component of the IMF: a high time resolution correlation analysis using EISCAT "polar" and AMPTE-UKS and IRM data, Planet. Space Sci., 36, 471, 1988.

Friis-Christensen, E., M. A. McHenry, C. R. Clauer, and S. Vennerstrøm, Ionospheric travelling convection vortices observed near the polar cleft: a triggered response to sudden changes in the solar wind, Geophys. Res. Lett., 15, 253, 1988.

Greenwald, R. A., K. B. Baker, R. A. Hutchins, and C. Hanuise, An HF phased-array radar for studying small-scale structure in the high-latitude ionosphere, Radio Sci., 20, 63, 1985.

Greenwald, R. A., K. B. Baker, J. R. Dudeney, M. Pinnock, T. B. Jones, E. C. Thomas, J.-P Villain, J.-C. Cerisier, C. Senior, C. Hanuise, R. D. Hunsucker, G. Sofko, J. Koehler, E. Nielsen, R. Pellinen, A. D. M. Walker, N. Sato, and H. Yamagishi, DARN/SUPERDARN: a global view of the dynamics of highlatitude convection, Space Sci. Rev., 71, 761, 1995.

Khan, H., and S. W. H. Cowley, Observations of the response time of high latitude ionospheric convection to variations in the interplanetary magnetic field using EISCAT and IMP-8 data, Ann. Geophysicae, 17, 1306, 1999.

Koskinen, H. E. J., R. E. Lopez, R. J. Pellinen, T. I. Pulkkinen, D. N. Baker, and T. Bösinger, Pseudobreakup and substorm growth phase in the ionosphere and magnetosphere, J. Geophys. Res., 98, 5801, 1993.

Lepping, R. P. et al., The WIND magnetic field investigation, Space Sci. Rev., 71, 207, 1995.

Lewis, R. V., M. P. Freeman, A. S. Rodger, G. D. Reeves, and D. K. Milling, The electric field response to the growth phase and expansion phase onset of a small isolated substorm, Ann. Geophysicae, 15, 289, 1997.

Lewis, R. V., M. P. Freeman, and G. D. Reeves, The relationship of HF radar backscatter to the accumulation of open magnetic flux prior to substorm onset, J. Geophys. Res., 104, 26,613, 1998.

Lockwood, M., and S. W. H. Cowley, Comment on "A statistical study of the ionospheric convection response to changing interplanetary field conditions using the assimilative mapping of ionospheric electrodynamics technique" by A. J. Ridley et al., J. Geophys. Res., 104, 4387, 1999.

Morelli, J. P., R. J. Bunting, S. W. H. Cowley, C. J. Farrugia, M. P. Freeman, E. Friis-Christensen, G. O. L. Jones, M. Lester, R. V. Lewis, H. Lühr, D. Orr, M. Pinnock, G. D. Reeves, P. J. S. Williams and T. K. Yeoman, Radar observations of auroral zone flows during a multiple-onset substorm, Ann. Geophysicae, 13, 1144, 1995.

Nagai, T., M. Fujimoto, R. Nakamura, Y. Saito, T. Mukai, T. Yamamoto, A. Nishida, S. Kokubun, G. D. Reeves, and 
R. P. Lepping, Geotail observations of a fast tailward flow at $\mathrm{X}_{\mathrm{GSM}}=-15 R_{E}, J$. Geophys. Res., 103, 23,543, 1998.

Nakamura, R., D. N. Baker, T. Yamamoto, R. D. Belian, E. A. Bering, J. R. Benbrook, and J. R. Theall, Particle and field signatures during pseudobreakup and major expansion onset, J. Geophys. Res., 99, 207, 1994.

Pulkkinen, T. I., D. N. Baker, M. Wiltberger, C. Goodrich, R. E. Lopez, and J. G. Lyon, Pseudobreakup and substorm onset: observations and MHD simulations compared, J. Geophys. Res., 103, 14,847, 1998.

Reiff, P. H., and J. L. Burch, IMF $B_{y}$-dependent plasma flow and Birkeland currents in the dayside magnetosphere 2. A global model for northward and southward IMF, J. Geophys. Res., 90, 1595-1609, 1985

Ridley A. J., G. Lu, C. R. Clauer, and V. O. Papitashvili, A statistical study of the ionospheric convection response to changing interplanetary magnetic field conditions using the assimilative mapping of ionospheric electrodynamics technique, J. Geophys. Res., 103, 4023, 1998.

Rodger, A. S., S. W. H. Cowley, M. J. Brown, M. Pinnock and D. A. Simmons, Dawn-dusk(y) component of the interplanetary magnetic field and the local time of the Harang discontinuity, Planet Space Sci., 8, 1021, 1984.

Ruohoniemi, J. M., and K. B. Baker, Large-scale imaging of high latitude convection with Super Dual Auroral Radar Network HF radar observations, J. Geophys. Res., 103, 20,797, 1998.

Ruohoniemi, J. M., and R. A. Greenwald, Observations of IMF and seasonal effects in high-latitude convection, Geophys. Res. Lett., 22, 1121-1124, 1995.

Ruohoniemi, J. M., and R. A. Greenwald, Statistical patterns of high-latitude convection obtained from Goose Bay HF radar observations, J. Geophys. Res., 101, 21,743, 1996.

Ruohoniemi, J. M., and R. A. Greenwald, The response of highlatitude convection to a sudden southward IMF turning, Geophys. Res. Lett., 25, 2913, 1998.

Ruohoniemi, J. M., R. A. Greenwald, K. B. Baker, J.-P. Villain, C. Hanuise, and J. Kelly, Mapping high-latitude plasma convection with coherent HF radars, J. Geophys. Res., 94, 13,463, 1989.

Shand, B. A., T. K. Yeoman, R. V. Lewis, R. A. Greenwald, and M. R. Hairston, Inter-hemispheric contrasts in the ionospheric convection response to changes in the Interplanetary Magnetic Field and substorm activity: a case study, Ann. Geophysicae, 16, 764, 1998.

Shepherd, S. G., R. A. Greenwald, and J. M. Ruohoniemi, A possible explanation for rapid, large-scale ionospheric responses to southward turnings of the IMF, Geophys. Res. Lett., 26, $3197,1999$.

Todd, H., S. W. H. Cowley, M. Lockwood, and D. M. Willis, Response time of the high-latitude dayside ionosphere to sudden changes in the north-south component of the IMF, Planet. Space Sci., 36, 1415, 1988.

Villain, J.-P., J. M. Ruohoniemi, R. A. Greenwald, and K. B. Baker, $\mathrm{HF}$ radar observations of $\mathrm{E}$ region plasma irregularities produced by oblique plasma streaming, J. Geophys. Res., 92, 12,327, 1987.

Wild, J. A., T. K. Yeoman, P. Eglitis, and H. J. Opgenoorth, Multiinstrument observations of the electric and magnetic field structure of omega bands, Ann. Geophysicae, 18, 99, 2000.

Wing, S., P. T. Newell, D. G. Sibeck, and K. B. Baker, A large statistical study of the entry of interplanetary magnetic field Y-component into the magnetosphere, Geophys. Res. Lett., 22, 2083, 1995.

Yeoman, T. K., and H. Lühr, CUTLASS/IMAGE observations of high latitude convection features during substorms, Ann. Geophysicae, 15, 692, 1997.

Yeoman, T. K., T. Mukai, and T. Yamamoto, Simultaneous ionospheric and magnetospheric observations of azimuthally propagating transient features during substorms, Ann. Geophysicae, 16, 754, 1998.

Yeoman, T. K., R. V. Lewis, S. E. Milan, and M. Watanabe, An interhemispheric study of the ground magnetic and ionospheric electric fields during the substorm growth phase and expansion phase onset, J. Geophys. Res., 104, 14,867, 1999. 